\title{
Perspectivas de Comunicação Pública da Ciência em Editais e Chamadas Públicas sobre Biodiversidade no Brasil
}

\section{Perspectives on Public Communication of Science Regarding Public Calls for Proposals on Biodiversity in Brazil}

\author{
Denise de Oliveira ${ }^{\circledR}$ Brasil \\ Danilo Giroldo Brasil \\ Martha Marandino ${ }^{\circledR}$ Brasil
}

\begin{abstract}
A presente pesquisa investigou editais e chamadas públicas sobre Biodiversidade do Conselho Nacional de Desenvolvimento Científico e Tecnológico - CNPq, com a intenção de compreender a integração entre o fomento à pesquisa e a divulgação científica ou popularização da ciência. Para tal, considera a relevância do incentivo às relações entre ciência e público em um País de megadiversidade e que enfrenta perdas e ameaças à biodiversidade e à diversidade cultural em todos os biomas brasileiros. Com base no referencial teórico dos modelos de comunicação pública da ciência, bem como por meio da aplicação da análise textual discursiva, foram analisados 32 editais e chamadas relacionados à biodiversidade, no período de 2005 a 2012, apontando perspectivas de comunicação pública da ciência em três grandes grupos: Informacional, de Diálogo e de Participação, cada qual revelando características próprias quanto à forma de socialização do conhecimento, concepção de ciência, concepção de público e de arranjos institucionais. Houve predominância do modelo informacional, em que a transferência do conhecimento é dirigida à sociedade e ao público em geral, de modo unidirecional, bem como de modelos mistos, em que a perspectiva informacional esteve associada à de diálogo e à de participação. Os resultados da pesquisa ampliaram a compreensão das ações de fomento à pesquisa sobre biodiversidade que vêm sendo integradas à divulgação e educação em ciências, dando margem ao aprimoramento de futuras ações, tanto de pesquisadores como de formuladores de editais, sobre a intenção de fortalecer o protagonismo da sociedade nos rumos da ciência e na conservação da biodiversidade.
\end{abstract}

Palavras-chave: biodiversidade; ciência-tecnologia-sociedade; editais e chamadas; comunicação pública da ciência.

This research investigated public calls for proposals on Biodiversity related issues of the Conselho Nacional de Desenvolvimento Científico e Tecnológico - CNPq (National Scientific and Technological Development Council), aiming at understanding the integration between the fostering of research and science communication or 
popularization. For that, the relevance of encouraging relations between science and the public sector in a country of huge diversity and facing losses and threats to biodiversity and cultural diversity in all Brazilian biomes was considered. Based on theoretical frameworks of public communication of science, as well as through the application of discursive textual analysis, we analyzed 32 public calls for proposals related to biodiversity, in the period from 2005 to 2012 revealing the outlook on the public communication of science in three major groups: Informational, on Dialogue and Participation groups. Also, each call for proposal reveals its own traits as to the socialization of knowledge, science conception, conception of public and institutional arrangements. There was prevalence of the information model, in which the transfer of knowledge is directed to society and the public at large, one-way oriented, as well as the mixed model, in which the informational perspective was associated with dialogue and participation. The results broadened the understanding of fostering actions to research on biodiversity that has been integrated into science communication and education, giving rise to the improvement of future actions, both to researchers and call for proposals managers, regarding the intention to strengthen society's main role in the paths of science and biodiversity conservation.

Keywords: biodiversity; science-technology-society; calls for proposals; public communication of science.

\section{Introdução}

O Brasil é considerado o país número um em diversidade biológica no mundo, dotado de imensa variabilidade de organismos vivos de todas as origens, com semelhanças e diferenças observadas nos diversos níveis do universo biológico, do molecular, passando pelo indivíduo, ao ecossistêmico e da paisagem, configurando-se, assim, um sistema fractal tanto no espaço como no tempo (Mittermeier et al., 2005; Trajano, 2010). Em todos os biomas brasileiros - Amazônia, Cerrado, Mata Atlântica, Caatinga, Pantanal, Campos Sulinos e Zona Costeiro-Marinha -, encontra-se expressiva sociodiversidade dos povos originários, com cerca de 900 mil brasileiros pertencentes a pelo menos 305 etnias indígenas (Instituto Brasileiro de Geografia e Estatística - IBGE, 2011), em 700 Terras Indígenas (Instituto Socioambiental - ISA, 2015), abrangendo cerca de 180 línguas, situadas entre as mais ameaçadas do mundo (SEKI, 1999). Possui ainda milhares de comunidades remanescentes de quilombos e de outras comunidades tradicionais. As perdas e as ameaças à biodiversidade e aos conhecimentos tradicionais, entretanto, estão presentes em todos os biomas, em um contexto mundial de declínio da biodiversidade e de aumento da degradação de hábitats (Declaração do Estado do Planeta, 2012; Scarano, 2007; Scarano, Guimaraes \& Silva, 2012; Secretariado da Convenção sobre Diversidade Biológica, 2014).

Esse panorama revela que os compromissos específicos assumidos pelo País como signatário da Convenção sobre Diversidade Biológica, bem como o reconhecimento da 
relevância da biodiversidade brasileira, expresso em inúmeras publicações científicas, não estariam sendo adequadamente considerados pelos tomadores de decisão, evidenciando a necessidade do aprimoramento da comunicação entre cientistas, gestores e amplos setores da sociedade, bem como a estruturação de um forte e amplo programa educacional (Lewinsohn, 2010; Metzger, Joly, Lewinsohn, Rodrigues \& Verdade, 2010; Scarano, 2007; Scarano \& Martinelli, 2010; Scarano et al., 2012; Trajano \& Varjabedian, 2009).

Essa condição requer uma reflexão sobre a complexidade, a incerteza e a urgência dos problemas ambientais como desafiadores dos fundamentos da ciência reducionista do Ocidente (Colucci-Gray, Dodman \& Camino, 2013), fazendo-se necessárias novas abordagens e processos de conhecimentos e de comunicação pública da ciência. Conforme Velho (2011), existe forte correlação entre os conceitos dominantes de ciência e a lógica das políticas de ciência, tecnologia e inovação, definidoras de paradigmas em cada momento histórico, determinando o foco, os instrumentos e as formas de gestão implementados. Defende assim que o momento atual está sendo o da construção de um novo paradigma da "ciência para o bem da sociedade", ou seja, uma ciência socialmente construída, com uma retomada do enfoque "nacional", e até mesmo do local, podendo ser direcionada pelas necessidades e preferências nacionais, culturalmente situada e construída.

As "Metas de Aichi para a Biodiversidade" para 2020 vão nesse sentido. Elaboradas durante a 10a Conferência dos Países membros (ou Partes) da Convenção, realizada em Nagoia, no Japão, em 18 de outubro de 2010, estão organizadas na forma de 20 metas voltadas para a redução da perda da biodiversidade, em âmbito mundial, em cinco grandes objetivos estratégicos. O primeiro deles se refere a tratar das causas fundamentais de perda de biodiversidade, de modo que as preocupações com a biodiversidade permeiem governo e sociedade (Secretariat of the Convention on Biological Diversity, 2010). No Brasil, a internalização das metas de Aichi resultou na Resolução da Conabio $n^{\circ}$ 6, de 3 de setembro de 2013 (Comissão Nacional da Biodiversidade, 2013), sendo que a Meta Nacional I estabelece que até 2020, no mais tardar, a população brasileira terá conhecimento dos valores da biodiversidade e das medidas que poderá tomar para conservá-la e utilizá-la de forma sustentável. Os objetivos estratégicos de tal meta abrangem atividades de pesquisa e de educação e popularização da ciência, pressupondo forte articulação com a política nacional de ciência, tecnologia e inovação.

Ao considerarmos o acesso às informações de ciência e tecnologia como um fator importante para o exercício pleno da cidadania, fortalecendo a formação de uma cultura científica e possibilitando a construção de uma visão crítica acerca do processo do conhecimento científico pelos cidadãos, reconhecemos a ciência e a tecnologia como processos sociais, com potencialidades, responsabilidades, limitações e fortes implicações para a sociedade (Santos \& Mortimer, 2001). Nesse contexto, têm lugar ações que buscam aproximar a relação entre ciência e público, por meio da divulgação científica ou popularização da ciência, da comunicação científica e da educação em 
ciências, da extensão, em contextos de educação formal, ligadas ao ensino, bem como da educação não formal, como em museus, centros de ciências, zoológicos, jardins botânicos, entre outros, unidades de conservação, em que se destaca a importância da educação em ciências sob a abordagem Ciência-Tecnologia-Sociedade (CTS).

Na avaliação do pioneiro Programa de Pesquisas em Caracterização, Conservação, Restauração e Uso Sustentável da Biodiversidade do Estado de São Paulo (BIOTAFAPESP), a aproximação entre ciência e público passa pelo uso do conhecimento para $\mathrm{o}$ atendimento das demandas da sociedade em questões relacionadas à biodiversidade, como recuperação de áreas degradadas, dados para subsidiar a legislação, capacitação de pessoal, entre outros. E, de modo especial, pelo subsídio à educação em todos os níveis, em contextos formais e não formais (Joly et al., 2010). Nesse sentido, foram levantadas questões sobre como aproximar o cientista da área educacional e sobre quais as abordagens necessárias, em muitas dimensões, como a atuação na educação formal e informal; a formação inicial e continuada de professores; a divulgação dos projetos de pesquisa em diferentes mídias de comunicação; a participação nos projetos de profissionais de uma variedade de áreas, principalmente biologia, educação e comunicação, objetivando produzir o diálogo necessário para construir colaborações sólidas com a educação básica. Um relevante passo dado por esse programa foi a abertura de uma chamada, no ano de 2015, de financiamento de projetos voltados à educação, por meio do BIOTA/ FAPESP Educação.

Em uma análise histórica da divulgação da ciência no Brasil, Moreira e Massarani (2002), ao mesmo tempo em que reconhecem importantes ações realizadas no País, ressaltam ser necessário um esforço consistente e coletivo para viabilizar o acesso ao conhecimento. Tal esforço abrange instituições de pesquisa, universidades, cientistas, comunicadores, educadores, estudantes e o público em geral para se alcançar um salto no amplo acesso das diferentes populações do País. Considera-se que o potencial de ação dessas instituições é muito maior do que o efetivamente realizado, tanto no âmbito da pesquisa e do ensino quanto no das atividades de extensão e de interação com a comunidade, nas quais a divulgação científica se insere (Moreira, 2006).

Os avanços em torno da divulgação científica brasileira são visíveis na comunicação pública da ciência e no jornalismo científico, na aplicação ao ensino e aos contextos de educação formal e não formal (Marandino, 2011; Santos, 2007; Santos \& Auler, 2011; Strieder \& Kawamura, 2014). Colocam-se ainda muitos desafios para a democratização do conhecimento e o protagonismo do público nas ações de produção e divulgação do conhecimento, de modo que se fortaleçam o pensamento crítico e investigativo, a explicitação de controvérsias e o diálogo de saberes, na construção de uma sociedade cada vez mais participativa (Marandino, 2009; Marandino, 2015; Marandino et al., 2008; Massarani, 2012; Massarani \& Moreira, 2009; Navas, Contier \& Marandino, 2007).

Para Navas e Marandino (2009), iniciativas em toda a América Latina em torno da divulgação e da popularização da ciência buscam articular ações de longo prazo que possam estabelecer relações sustentáveis entre a ciência e a sociedade. Tem 
destaque no Brasil o processo democrático de planejamento da política nacional de ciência e tecnologia, de modo especial, as quatro conferências nacionais de Ciência, Tecnologia e Inovação, ocorridas entre 1985 e 2010 (Ministério da Ciência e Tecnologia - MCT, 2010). Em torno delas houve um processo de planejamento participativo, com conferências regionais prévias, e que culminaram com importantes conquistas, como a criação do Departamento de Popularização da Ciência, em 2003, no então Ministério da Ciência e Tecnologia, na Secretaria de Ciência e Tecnologia para Inclusão Social (SECIS). Outra conquista relevante foi o estabelecimento, no planejamento da política nacional de ciência, tecnologia e inovação, de uma prioridade estratégica relacionada à Ciência, Tecnologia e Inovação para o Desenvolvimento Social, com a criação da Semana Nacional de Ciência e Tecnologia, realizada anualmente no País, dos centros vocacionais tecnológicos, bem como do lançamento de vários editais e chamadas conjuntos do MCTI e do CNPq pela popularização da ciência, como os referentes aos centros e museus de ciências, olimpíadas de ciências e ciência móvel. Destaca-se ainda a criação do Comitê Assessor de Divulgação Científica (CA - DC), pelo CNPq, a concessão de bolsa de Produtividade em Pesquisa para essa área e a criação de uma nova aba do Currículo Lattes, referente à Educação e Popularização de Ciência e Tecnologia (C\&T). Ao lado dessas importantes ações para a popularização da ciência, que incluem editais e chamadas públicas temáticas, sobressai-se a inserção do fomento à divulgação científica em ações e programas de pesquisa que enfocam a biodiversidade, no CNPq, sendo esse universo em particular nosso interesse de investigação.

Navas e Contier (2015) afirmam que um olhar crítico sobre programas e projetos de divulgação científica pode contribuir para promover o engajamento e a participação dos cidadãos como elementos estruturantes das relações entre ciência e sociedade, na perspectiva de análise no âmbito do movimento Ciência-Tecnologia-Sociedade. No contexto da América Latina, em que a necessidade de aumentar a participação da sociedade e do fortalecimento do processo democrático é compartilhada por muitos países, esse movimento almeja o fortalecimento da participação da sociedade. Esta participação envolve, por um lado, a compreensão crítica sobre questões relacionadas à CTS, considerando que ciência e tecnologia estão cada vez mais presentes na sociedade. Por outro, e assumindo a perspectiva freireana de educação, tal participação propõe uma leitura crítica do mundo, numa possibilidade de desvelamento da realidade para sua transformação (Auler, 2002; Strieder \& Kawamura, 2014). Pode ainda dar margem a ampliar a compreensão em torno das ações institucionais relacionadas à educação e à divulgação científica, permitindo que a instituição possa adequá-las aos seus objetivos e intenções (Souza, 2009). Ambiciona-se, assim, uma educação científica que busque o desenvolvimento de compromissos e a transformação do mundo, com caminhos de intervenção na realidade com o intuito de transformá-la, por meio da participação social (Strieder, 2012; Strieder \& Kawamura, 2014).

Desse modo, vários autores vêm propondo modelos de comunicação pública da ciência, como referenciais de análise de diferentes dimensões e objetivos relacionados às 
experiências e práticas voltadas à divulgação da ciência. Consideramos assim relevantes pesquisas sobre as ações governamentais de popularização da ciência, que permitam caracterizar a forma na qual esses espaços e atores assumem compromissos com a divulgação científica, a popularização da C\&T e a promoção da cultura científica na sociedade, objetivando compreender quais os modelos de comunicação pública seriam evidenciados entre a ciência e a sociedade (Navas \& Marandino, 2009).

Diante desse contexto, buscamos investigar, em um conjunto de editais e chamadas sobre a biodiversidade do $\mathrm{CNPq}$, quais perspectivas de comunicação pública da ciência estariam presentes e ausentes, de modo a ampliar a compreensão sobre como está sendo feita a integração do fomento sobre biodiversidade às ações de educação e de divulgação científica. Esses dados nos levam a perceber pelo menos dois aspectos relevantes no que se refere às políticas científicas no Brasil. O primeiro refere-se à compreensão de como está sendo construída a relação entre biodiversidade e educação/comunicação por meio do fomento à pesquisa, já que esta é uma das metas de Aichi, firmadas pelo País. O segundo aspecto que os dados expressam refere-se à análise de como o Brasil tem incorporado a dimensão educativa e de comunicação em seus financiamentos voltados à pesquisa sobre biodiversidade, revelando o compromisso em termos de política científica do País em direção à democratização do conhecimento sobre a biodiversidade.

\section{Aspectos metodológicos da análise dos editais e chamadas sobre biodiversidade}

Em uma primeira etapa, de caráter documental, foi feito um levantamento na página do CNPq (http://www.cnpq.br), em Chamadas - encerradas, no período entre 2005 a 2012, relacionados à biodiversidade, buscando pelos principais programas de pesquisa sobre biodiversidade. Até 2010, tais documentos eram denominados editais e em seguida passaram a ser chamadas. Foram igualmente observados programas em que esse tema apareceu como área elegível de pesquisa, não tendo sido incluídos editais e chamadas de cooperação internacional. A análise de tais documentos de cooperação internacional, por envolver agências de fomento internacionais, implicaria em um estudo de natureza diferente daquele proposto neste trabalho. Entendemos, contudo, que este tipo de análise poderá ser feita em trabalhos futuros.

O período dos editais e chamadas selecionados deve-se à disponibilidade da consulta eletrônica, a partir de 2005, sendo 2012 o início da coleta de dados. Foram levantados, assim, 32 editais e chamadas, que não esgotam as ações em biodiversidade do $\mathrm{CNPq}$, mas representam importantes programas de pesquisa, listados a seguir (Quadro 1). Estão nesse levantamento programas específicos de biodiversidade, como o PPBio, Sisbiota, Bionorte; programas em que a biodiversidade é uma dentre outras áreas prioritárias de pesquisa, como o edital dos Institutos Nacionais de Ciência e Tecnologia (INCT); e, ainda, ações de fomento relacionadas à biodiversidade em um contexto cultural, como o edital que visa promover a sustentabilidade agrícola em bases ecológicas, nos quais destaca-se a inserção de povos indígenas, comunidades 
tradicionais, agricultores familiares, entre outros.

Quadro 1. Editais e Chamadas sobre Biodiversidade do CNPq analisados e respectivos programas/temas associados

1. Edital MCT/CNPq nº 01/2005 (Institutos do Milênio);

2. Edital CT-BIOTEC/MCT/CNPq nº 021/2005 (Coleções Biológicas);

3. Edital MCT/MMA/SEAP/SEPPIR/CNPq 26/2005 (Extensão e tecnologias sociais);

4. Edital CT-Hidro/MCT/CNPq no 37/2005 (Ecorregiões Aquáticas);

5. Edital MCT/CNPq/PPG7 no 48/2005 (SPC\&T Fase II/ PPG7);

6. Edital Programa Arquipélago e Ilhas Oceânicas/CNPq nº 056/2005 (Proarquipélago);

7. Edital CNPq nº 055/2005 - PROANTAR (Programa Antártico Brasileiro);

8. Edital MCT/ CNPq/ CT-Hidro nº 039/2006 (Bioindicadores de qualidade da água);

9. Edital MCT/ CNPq/CT-Hidro nº 044/2006 (Áreas úmidas brasileiras);

10. Edital MCT/ CNPq/ CT-Hidro nº 045/2006 (Vazão ecológica);

11. Edital MCT/CT-HIDRO/MMA/CNPq nº 29/2007 (Gestão de águas, mapeamento de sensibilidade ambiental ao óleo da zona costeira e marinha);

12. Edital MCT/CNPq/SEAP-PR/CT-Agronegócio/CT-Verde Amarelo/CT-Saúde/CT-Hidro n ${ }^{\circ}$ 07/2008 SEAP (Tecnologias para a agricultura familiar de base ecológica, comunidades tradicionais e povos indígenas);

13. Edital no 15/2008 - MCT/CNPq/FNDCT/ CAPES/FAPEMIG/ FAPERJ/ FAPESP/ INSTITUTOS NACIONAIS DE CIÊNCIA E TECNOLOGIA (INCT);

14. Edital MCT/CNPq no 023/2009 (Programa Antártico Brasileiro);

15. Edital MCT/CNPq/CT-AGRO n 24/2009 (Redes de Pesquisa sobre Polinizadores);

16. Edital MCT/CNPq nº 026/2009 (Proarquipélago);

17. Edital MCT/CNPq/MDA/SAF/Dater no 033/2009 (Extensão rural no âmbito da agricultura familiar, povos indígenas e comunidades tradicionais);

18. Edital MCT/CNPq/CT-Petro no 39/2009 (Potencial biotecnológico da biodiversidade costeira e marinha);

19. Edital MCT/CNPq n 59/2009 PELD (Programa de Pesquisas Ecológicas de Longa Duração); 20. Edital MCT/CNPq/FNDCT-AÇÃO TRANSVERSAL/ CTAMAZÔNIA/ CT-BIOTEC/ BIONORTE n 066/2009 (Rede Bionorte de Ensino e Pesquisa da Amazônia Legal);

21. Edital MCT/CNPq/MEC/CAPES/CT AGRO/CT HIDRO/FAPS/EMBRAPA no 22/2010

- REPENSA (Redes de pesquisa, desenvolvimento e inovação em Agrobiodiversidade e sustentabilidade na agropecuária brasileira);

22. Edital MCT/ CNPq/FNDCT/FAPs/MEC/CAPES/PRO-CENTRO-OESTE n ${ }^{\circ}$ 031/2010

(Programa Pró-Centro-Oeste para a conservação e ao uso sustentável dos recursos naturais do Cerrado e do Pantanal);

Fonte: $\mathrm{CNPq}$ (http://www.cnpq.br/). 
Quadro 1. Editais e Chamadas sobre Biodiversidade do CNPq analisados e respectivos programas/temas associados - continuação

23. Edital MCT/CNPq/MMA/MEC/CAPES/FNDCT - Ação Transversal/FAPs nº 47/2010 SISBIOTA (Programa Sistema Nacional de Pesquisa em Biodiversidade);

24. Edital MCT/CNPq/FNDCT n 50/2010 (Rede de identificação Molecular da Biodiversidade BR-BoL);

25. Edital MCT/CNPq/MEC/CAPES No 52/2010 - PROTAX (Programa de Capacitação em Taxonomia);

26. Edital MCT/ CNPq/FNDCT/ MEC/CAPES/FAPs nº 56/2010 - REFLORA (Resgate, uso e disponibilização online, no Herbário Virtual para o Conhecimento e Conservação da Flora Brasileira);

27. Edital MCT/CNPq/FNDCT nº 71/2010 (Institutos Nacionais de Ciência e Tecnologia em Ciências do Mar);

28. Chamada CNPq/ICMBio no 13/2011 (Pesquisa em Unidades de Conservação Federais);

29. CHAMADA MCTI/CNPq/FAPs n 34/2012 PELD (Programa de Pesquisas Ecológicas de Longa Duração);

30. Chamada MCTI CNPq/ No 35/2012 - PPBio/Geoma (Programa de Pesquisa em Biodiversidade/ Redes de Pesquisa, Monitoramento e Modelagem em Biodiversidade e Ecossistemas);

31. Chamada CNPq no 39/2012 (PROARQUIPÉLAGO);

32. Chamada MCTI/CNPq no 45/2012 (Sistema de Informações sobre a Biodiversidade Brasileira $\mathrm{SiBBr})$.

A análise dos documentos foi feita a partir do referencial teórico da Análise Textual Discursiva (ATD) (Moraes \& Galiazzi, 2007). A ATD tem seus fundamentos na fenomenologia e na hermenêutica, valorizando a procura de novos sentidos que necessitam ser produzidos no processo, visando ampliar os pontos de vista e as compreensões possíveis em torno do fenômeno investigado. Desse modo, consideramos os editais e chamadas como textos apropriados para a ATD, uma vez que essa análise tende a perceber seus objetos de pesquisa como discursos, não como fenômenos ou conceitos isolados, dando margem a reconstruir os significados e discursos que investiga nos dados ou "corpus" textuais da análise (Moraes \& Galiazzi, 2007). A ATD abrange um processo de unitarização ou desconstrução do corpus, bem como de categorização, em que são estabelecidas relações entre os elementos unitários de um conjunto de materiais linguísticos e discursivos, por meio dos quais é possível captar a emergência de uma nova compreensão e comunicar novos entendimentos sobre os fenômenos investigados.

Em cada etapa, buscamos assegurar a validade da análise; observamos, na etapa de unitarização, a pertinência das unidades de significado aos objetivos da pesquisa e até que ponto unidades novas ainda expressavam sentidos novos e significativos para a pesquisa, de modo que as unidades mantivessem ao mesmo tempo conexão com o fenômeno estudado e dessem margem a atingir níveis de compreensão mais profundos. $\mathrm{Na}$ etapa de categorização, em que estão envolvidos aspectos dedutivos, indutivos e 
intuitivos por parte do pesquisador, observamos a validade e pertinência das categorias emergentes. Tivemos também a validação das categorias pelos professores orientadores desta pesquisa (orientador e coorientadora), tendo em vista a busca da confiabilidade da pesquisa qualitativa (Alves-Mazzotti \& Gewandsznajder, 2004). Uma vez que a ATD inicia-se com a fragmentação dos textos, concretizada por uma ou mais leituras em que identifica-se cada fragmento a ser destacado, cada documento foi lido integralmente, buscando-se no texto qual conteúdo traziam quanto ao fomento à educação e divulgação, ou seja, identificando o discurso associado a esses elementos nos editais e chamadas. $\mathrm{Na}$ sequência, realizamos uma segunda leitura, buscando pelos seguintes termos pertinentes à temática: diálogo, público, educação, divulgação, popularização, comunicação, difusão, sociedade, transferência de conhecimento, ensino, didática, capacitação, formação, informação, treinamento, transferência de tecnologia, disseminação, extensão, educação formal, educação informal, educação não formal, popularização, arte, apropriação, participação e multi/inter/transdisciplinaridade. Em seguida, procedemos à transcrição dos conteúdos encontrados.

Houve também intensa leitura e impregnação em referenciais teóricos, em especial os referentes às concepções em torno dos modelos de comunicação pública da ciência.

Por meio do processo de desconstrução e reconstrução da análise, percebemos emergir um conjunto de aspectos relacionados a formas de socialização do conhecimento, tipos de público, arranjos institucionais e concepções de ciência/processos de conhecimento, que não conhecíamos à priori e nas quais reconhecemos a presença dos modelos de comunicação pública. Tais categorias possuem as seguintes características: a) formas de socialização do conhecimento, ou seja, os modos de expressar a relação entre ciência e público, abrangendo desde a disseminação para os pares ou em uma única via dos cientistas ao público em geral; divulgação para diferentes públicos, troca entre cientista e público, até formas descentralizadas e não hierárquicas, de modo coletivo, em coconstrução; b) concepção da ciência, englobando concepções neutras, acríticas; conhecimento disciplinar e fragmentado; multidisciplinaridade; ciência dinâmica, histórica, implicada socialmente, com diálogo entre campos e áreas de conhecimento, incluindo a educação e comunicação; interdisciplinaridade; consideração de ciência equiparada a outras formas de conhecimento, como os saberes das comunidades e os saberes tradicionais; interculturalidade; diálogo de saberes; c) concepção de público, abarcando público homogêneo ou heterogêneo, passivo, participante, crítico, ativo, leigo ou dotado de saberes, com conhecimentos prévios; d) arranjos institucionais, entendidos como uma determinada maneira proposta ou exigida, como as relações serão articuladas para o alcance dos objetivos, ou seja, o modo como os editais recomendam, exigem ou vetam as relações entre instituições, agências e instâncias, tais como redes cooperativas, vinculação da proposta à pós-graduação, à educação básica, à extensão universitária, entre outros.

Por fim, os 32 editais e chamadas foram analisados buscando evidenciar se como 
os modelos de comunicação pública estavam presentes em seus pressupostos e ações.

\section{A quais perspectivas de comunicação pública da ciência estamos nos referindo?}

A comunicação pública da ciência vem sendo considerada uma disciplina emergente e interdisciplinar e que tem crescido nas últimas décadas em intersecções com a educação em ciências, estudos sociais da ciência, comunicação de massa, museologia, entre outras. Nela, a proposição dos modelos de comunicação pública da ciência são considerados uma das questões chave da agenda da pesquisa teórica (Bucchi \& Trench, 2016; Trench \& Bucchi, 2010).

Lewenstein (2003) e Lewenstein e Brossard (2006) propuseram quatro modelos para descrever atividades de comunicação pública da ciência no jornalismo científico, nos museus de ciência e nos programas sobre ciência de impacto na comunidade: o modelo de déficit, contextual, da expertise leiga e o modelo de participação pública. $\mathrm{O}$ modelo de déficit é conhecido também como modelo de cima para baixo (top down) e tem caracterizado muitas décadas das práticas de divulgação científica, na qual está parte dos especialistas (no alto), e tem como destino final um público passivo que a recebe (embaixo), do qual não se espera conhecer sua forma de apropriação ou uso (Navas \& Marandino, 2009). O modelo contextual, apesar de próximo, se diferenciaria do modelo de déficit ao não considerar as pessoas como recipientes vazios para a informação, mas que a processam a partir de experiências prévias, do contexto cultural e de circunstâncias pessoais que modelam seus esquemas sociais e psicológicos. Para Cheng et al. (2008), entretanto, o modelo contextual, embora em um tom distinto, teria as mesmas premissas do modelo de déficit, ou seja, ciência e sociedade seriam concebidas como autônomas e distintas uma da outra, em que a primeira prevaleceria sobre a outra.

Os modelos de déficit e contextual têm sido agrupados, de forma genérica, em "modelos de déficit", já que o foco em ambos os casos é a informação. Segundo Massarani (2012), equacionariam a questão da compreensão pública da ciência mais do ponto de vista da apreciação pelo público dos benefícios da ciência à sociedade, não abordando adequadamente o contexto social e político no qual as instituições científicas de poder usam a alfabetização científica como ferramenta retórica para influenciar decisões políticas e de financiamento, algumas vezes em oposição política aos interesses locais.

Por outro lado, os modelos de expertise leiga e de participação vêm sendo considerados modelos dialógicos ou de participação (Lewenstein \& Brossard, 2006), com foco nos sujeitos envolvidos no processo. No modelo de expertise leiga, baseado na vida real e nas experiências das comunidades, busca-se reconhecer informações, conhecimento e expertise das comunidades que estão enfrentando questões científicas e tecnológicas, para valorizar o conhecimento local como conhecimento especializado em seu próprio direito. Já no modelo de participação pública, há o compromisso de democratização do conhecimento e se valoriza o diálogo entre o cientista e o público. Também chamado de modelo de engajamento público, é ligado ao ideal democrático 
de ampla participação pública no processo político. Aspectos essenciais dos modelos participativos de comunicação pública da ciência estão presentes na educação em ciências com abordagem Ciência-Tecnologia-Sociedade (CTS), tendo entre eles: (1) a promoção da participação cidadã e a tomada de decisão em assuntos de C\&T em prol da democratização do conhecimento científico; (2) a rejeição da "deficiência do público" como foco das relações entre ciência e sociedade (Auler, 2002) e, consequentemente, a valorização dos conhecimentos e das experiências prévias ante o conhecimento científico e o tecnológico; e (3) o reconhecimento da natureza interativa, dinâmica e controversa da ciência (Navas et al., 2007; Contier, Navas \& Marandino, 2007).

Strieder e Kawamura (2014), ao analisar a produção CTS na área de Educação em Ciências para investigar formas de participação social, identificaram diferentes categorias, associadas a diferentes níveis de crítica: (I) busca pelo reconhecimento da presença da C\&T na sociedade; (II) avaliação de pontos positivos e negativos associados ao uso de determinado resultado/produto da C\&T; (III) discussão de problemas, impactos e transformações sociais da C\&T; (IV) identificação de contradições e estabelecimento de mecanismos de pressão; e (V) compreensão das políticas públicas e participação no âmbito das esferas políticas.

Navas e Marandino (2009) realizaram a análise dos tipos de atividades de popularização da ciência desenvolvidas pelo Ministério da Ciência e Tecnologia no período de 2003 a 2006, com base em dados coletados em documentos oficiais e entrevistas realizadas. A partir dos modelos de comunicação pública, bem como do aprofundamento teórico nos temas de referência da pesquisa, contextualizados na área de estudos sociais sobre a ciência, as autoras definiram os dois modelos, da seguinte forma: a) atividades informativas, que abrangem processos e ações que: 1) buscam disseminar informação sobre ciência e tecnologia em amplos setores da sociedade; 2) tendem a conceber a ciência como um corpo de conhecimentos dado e um conjunto de eventos neutros que podem ser transmitidos dos especialistas para o público; e 3) consideram o público como leigo em assuntos de ciência e tecnologia e, em consequência, como ator passivo e um grupo único com características homogêneas; b) atividades dialógicas, que consideram processos e ações que: 1 ) buscam uma negociação de conhecimentos entre público, cientistas e outros agentes relacionados com a ciência e tecnologia; 2) tendem a conceber a ciência em uma perspectiva dinâmica e humana; e 3) consideram o público como ator ativo, com características heterogêneas, conhecimentos prévios sobre CTI e outras áreas relevantes para a solução de problemas reais, com direito e capacidade de ser crítico e de participar em processos de tomada de decisões.

Destacamos Navas e Contier (2015), que avaliam que, dependendo do objetivo, podem ser enfatizados processos de comunicação em via única ou dupla, conteúdos ou contextos, públicos passivos ou ativos, sintetizando essa tendência em três modelos de comunicação: déficit, diálogo e participação, adaptados de Bucchi (2008), da seguinte maneira: (1) modelo de déficit: a ênfase é no conteúdo, e a tendência de comunicação é unidirecional, ou seja, a comunicação se estabelece em uma única via, dos especialistas 
aos não especialistas, com o objetivo de transferir os conhecimentos científicos; (2) modelo de diálogo: a ênfase é no contexto, e a tendência de comunicação é bidirecional, ou seja, espera-se que a comunicação se estabeleça em mão dupla, dos especialistas aos não especialistas e vice-versa, com o objetivo de compartilhar e negociar saberes por meio de diálogo e discutir as implicações dos conhecimentos; e (3) modelo de participação: a ênfase é no conteúdo e no contexto, e a tendência de comunicação é multidirecional e incerta, ou seja, os processos de comunicação não têm vias nem ênfases definidas, sendo o objetivo criar conhecimentos de maneira conjunta, sem que haja uma forma dominante em que isso possa ser feito; nele abre-se espaço para que as divergências possam conviver; contribuir na pauta do desenvolvimento científico. Consideramos, aqui, a distinção entre uma perspectiva de diálogo e de participação, com a intenção de diferenciar situações em que o diálogo esteja presente, em duas vias; com discussões das implicações do conhecimento, mas cujo nível de participação e engajamento não seria ainda enfatizado. Na perspectiva de participação estaria presente o que entendemos por uma dialogicidade na perspectiva freireana, favorecedora de uma efetiva participação (Santos, 2008).

Tomando por base os trabalhos de Navas e Marandino (2009) e Navas e Contier (2015), realizamos a análise dos 32 editais e chamadas, indicando como esses documentos assumem as perspectivas de comunicação pública da ciência, tanto isoladamente como de forma associada, a partir das seguintes categorias:-

Modelo Informacional: nesta perspectiva predomina a transferência unidirecional de conteúdos científicos dos cientistas para públicos amplos e a sociedade em geral, na forma de conteúdos isolados, de modo neutro e sem articulação entre as instituições para o seu alcance: a) forma de socialização do conhecimento: posteriormente à produção de conhecimento; disseminada, transferida, facultada de forma genérica para os pares ou para o público em geral; disponibilização de informações e resultados em bancos de dados - o alvo é o público amplo, a sociedade em geral, não havendo distinção ou foco específico; feita por cientistas, em uma única via; b) concepção de ciência: neutra e acrítica; corpo de conhecimento dado (ahistórica); disciplinar, sem diálogo entre campos/áreas diferentes; c) concepção de público: leigo, passivo, homogêneo; d) arranjos institucionais: isolados, sem proposta de articulação entre diferentes agências e instâncias.

Modelo de Diálogo: nesta perspectiva, a troca se dá de modo bidirecional, do cientista para o público e deste para com o cientista, ressaltando o contexto, com a participação da sociedade se dando no âmbito da avaliação de aspectos positivos e negativos resultantes das pesquisas: a) forma de socialização do conhecimento: divulgação para diferentes públicos, considerando seus saberes e seu contexto; compartilhamento feito por ambos, ciência e público, por meio do diálogo; bidirecional; b) concepção de ciência: dinâmica, histórica, processual e implicada socialmente; o processo de conhecimento se dá na interdisciplinaridade, com diálogo entre campos e áreas, incluindo as ambientais, de educação e de comunicação; c) concepção de público: 
heterogêneo, com ideias e concepções sobre a ciência, que discute e constrói visões críticas sobre ela; d) arranjos institucionais: estabelece relação entre as instâncias com agências de fomento, entre as finalidades de ensino, pesquisa e extensão.

Modelo de Participação: nesta perspectiva, o enfoque é tanto no conteúdo como no contexto. A tendência de comunicação é multidirecional e incerta, ou seja, os processos de comunicação não têm vias definidas ou hierárquicas, e o objetivo é criar conhecimentos de maneira conjunta, em coconstrução, sem que haja uma forma dominante em que isso possa ser feito, abrindo espaço para explicitar divergências e para participação na pauta do desenvolvimento científico (Navas \& Contier, 2015): a) formas de socialização do conhecimento: múltiplas e descentralizadas, sem vias definidas, feitas de forma coletiva, por diferentes agentes, observando conteúdo e contexto; coconstrução; b) concepção de ciência: o conhecimento não é produzido somente nas instâncias legitimadas pela ciência, pois se consideram outras formas de saber e o saber leigo; saber das comunidades; interdisciplinaridade considerando saberes locais; metodologias participativas; interculturalidade; diálogo de saberes; c) concepção de público: heterogêneo; participa, contribui na pauta do desenvolvimento científico; toma decisões; público define o que e como divulgar a partir de sua agenda, de seu interesse; d) arranjos institucionais: redes (sem hierarquia); relações não hierárquicas entre as instâncias.

\section{Perspectivas de comunicação pública da ciência nos editais e chamadas sobre biodiversidade do CNPq}

Percebemos a ocorrência da perspectiva informacional em vinte e um editais e chamadas; da perspectiva informacional associada à perspectiva de diálogo, em sete documentos; da perspectiva informacional, de diálogo e de participação, em um documento; e da perspectiva de diálogo e de participação destacadas, em três documentos.

Nos documentos em que observamos apenas a perspectiva informacional, identificamos desde a situação em que a divulgação científica não está explícita e a disseminação do conhecimento é dirigida aos pares, passando pela evocação a ações de divulgação científica, mas sem mencionar tipos de públicos ou ainda referindose a públicos genéricos, como sociedade ampla ou sociedade em geral. Os arranjos institucionais são pouco diversificados, com pouca articulação com a pós-graduação e com a CAPES (Quadro 2). 
Quadro 2. Características da perspectiva informacional em editais e chamadas sobre biodiversidade (2005-2012)

\begin{tabular}{|c|c|}
\hline Características & Perspectiva Informacional \\
\hline $\begin{array}{l}\text { Formas de socialização } \\
\text { do conhecimento }\end{array}$ & $\begin{array}{l}\text { Disseminação para os } \neg \text { pares; transferência do conhecimento, de informações, } \\
\text { de resultados e de tecnologias; subsídio à tomada de decisão à gestão } \\
\text { ambiental; criação de página na internet de divulgação do projeto e de seus } \\
\text { impactos; plataformas e sistemas integrados de informação de coleções de } \\
\text { interesse biotecnológico; potencial de divulgação; síntese do conhecimento } \\
\text { para consolidar as informações para propiciar a divulgação científica, a } \\
\text { tomada de decisões e a formulação de políticas públicas; fornecimento de } \\
\text { dados e apoio a sistemas de informação, de base de dados e gerenciamento de } \\
\text { repositórios da informação sobre a biodiversidade brasileira. }\end{array}$ \\
\hline Tipos de público & $\begin{array}{l}\text { Sem menção aos tipos de público ou público genérico, como público } \\
\text { em geral, grande público, sociedade em geral, público beneficiário; } \\
\text { formuladores de políticas públicas, comunidades locais. }\end{array}$ \\
\hline $\begin{array}{l}\text { Arranjos } \\
\text { institucionais }\end{array}$ & Pouco diversificados. \\
\hline $\begin{array}{l}\text { Concepção de } \\
\text { ciência/processo de } \\
\text { conhecimento }\end{array}$ & $\begin{array}{l}\text { Sem menção; conhecimento disciplinar; redes; multidisciplinaridade } \\
\text { interdisciplinaridade, quando presente, não é associada à divulgação } \\
\text { científica. }\end{array}$ \\
\hline \multicolumn{2}{|r|}{ Editais e Chamadas } \\
\hline \multicolumn{2}{|c|}{ Edital MCT/CNPq no 01/2005 (Institutos do Milênio); } \\
\hline \multicolumn{2}{|c|}{ Edital CT-BIOTEC/MCT/CNPq nº 021/2005 (Coleções biológicas); } \\
\hline \multicolumn{2}{|c|}{ Edital CT-Hidro/MCT/CNPq nº 37/2005 (Ecorregiões Aquáticas); } \\
\hline \multicolumn{2}{|c|}{ Edital MCT/CNPq/ PPG7 nº 48/2005 (SPC\&T Fase II/PPG7); } \\
\hline \multicolumn{2}{|c|}{ Edital CNPq nº 055/2005 (PROANTAR); } \\
\hline \multicolumn{2}{|c|}{ Edital MCT/CNPq nº 026/2009 (Proarquipélago); } \\
\hline \multicolumn{2}{|c|}{ Edital MCT/CNPq/CT-Hidro - nº 039/2006 (Bioindicadores de qualidade da água); } \\
\hline \multicolumn{2}{|c|}{ Edital MCT/CNPq/CT-Hidro no 044/2006 (Áreas úmidas brasileiras); } \\
\hline \multicolumn{2}{|c|}{ Edital MCT/CNPq/CT-Hidro nº 045/2006 (Vazão ecológica); } \\
\hline \multicolumn{2}{|c|}{$\begin{array}{l}\text { Edital MCT/CT-HIDRO/ MMA/CNPq n 29/2007 (Gestão de águas, mapeamento de sensibilidade } \\
\text { ambiental ao óleo das zonas costeira e marinha); }\end{array}$} \\
\hline \multicolumn{2}{|c|}{$\begin{array}{l}\text { Edital MCT/CNPq/CT-Petro no 39/2009 (Potencial biotecnológico da biodiversidade costeira e } \\
\text { marinha); }\end{array}$} \\
\hline \multicolumn{2}{|c|}{ Edital MCT/CNPq nº 59/2009 (PELD); } \\
\hline \multicolumn{2}{|c|}{$\begin{array}{l}\text { Edital MCT/CNPq/FNDCT-AÇÃO TRANSVERSAL/CTAMAZÔNIA/CT-BIOTEC/BIONORTE no } \\
\text { 066/2009 (Programa Bionorte); }\end{array}$} \\
\hline \multicolumn{2}{|c|}{ Edital MCT/CNPq/ MEC/CAPES/CTAGRO/CT-HIDRO/ FAPS/EMBRAPA n 22/2010 } \\
\hline \multicolumn{2}{|l|}{ (Repensa); } \\
\hline & \\
\hline
\end{tabular}

Fonte: Dados da pesquisa dos autores 
Quadro 2. Características da perspectiva informacional em editais e chamadas sobre biodiversidade (2005-2012) - continuação

\begin{tabular}{|l|}
\hline \multicolumn{1}{|c|}{ Editais e Chamadas } \\
\hline Edital MCT/CNPq/MEC/CAPES no 52/2010 (PROTAX); \\
Edital CNPq no 056/2005 - Programa Arquipélago e Ilhas Oceânicas (Proarquipélago); \\
CHAMADA MCTI/CNPq/FAPs nº 34/2012 (PELD); \\
Chamada MCTI/CNPq/ no 35/2012 (PPBio/ Geoma); \\
Chamada CNPq no 39/2012 (Proarquipélago); \\
Chamada MCTI/CNPq no 45/2012 (Sistema de Informações sobre a Biodiversidade Brasileira - \\
SiBBr).
\end{tabular}

Fonte: Dados da pesquisa dos autores

Nos documentos em que identificamos a perspectiva informacional associada à perspectiva de diálogo, em sete documentos, ou ainda às perspectivas de diálogo e de participação, em um documento, os aspectos informacionais estão presentes nas formas de socialização do conhecimento que demandam a transferência de resultados e de informações. Nota-se uma diferenciação maior dos tipos de público, como, por exemplo, em agricultores, populações costeiras, gestores e comunidades no entorno das unidades de conservação. São propostos processos de conhecimento em rede, em articulação com a pós-graduação e a educação básica, com a participação da CAPES, evocando arranjos institucionais mais diversificados. Surge a obrigatoriedade do plano ou estratégia de divulgação científica, associado à interdisciplinaridade, pressupondo o envolvimento de profissionais de distintas áreas, incluindo as ambientais, de educação e comunicação, dando margem ao diálogo. Na Chamada CNPq/ICMBio n 13/2011, a consideração de que a pesquisa deverá subsidiar a gestão participativa das unidades de conservação, bem como a solução de conflitos de modo integrado às comunidades locais e aos gestores das unidades de conservação e em seu entorno no Bioma Caatinga, evoca uma perspectiva de diálogo e de construção conjunta daquilo que se pretende alcançar - a gestão participativa das unidades de conservação, a solução de conflitos de modo integrado, evocando uma perspectiva de participação (Quadro 3).

Quadro 3. Características da perspectiva informacional associada às perspectivas de diálogo e de participação em editais e chamadas sobre biodiversidade (2005-2012)

\begin{tabular}{|l|l|}
\hline Características & Perspectiva Informacional, de diálogo e de participação \\
\hline Formas de & Dados e informações devem ser disponibilizados em base de dados ou \\
socialização do & sistemas de informação; Difusão e transferência do conhecimento ações para a \\
conhecimento & $\begin{array}{l}\text { democratização do conhecimento, com envolvimento de equipe interdisciplinar } \\
\text { desde o início da pesquisa; apropriação do conhecimento de diferentes níveis de } \\
\text { ensino formal e não formal, bem como população em geral e gestores públicos; } \\
\text { criação de ambiente atraente e estimulante para alunos talentosos de diversos } \\
\text { níveis, do ensino médio à pós-graduação. }\end{array}$ \\
\hline
\end{tabular}


Quadro 3. Características da perspectiva informacional associada às perspectivas de diálogo e de participação em editais e chamadas sobre biodiversidade (2005-2012)- continuação

\begin{tabular}{|c|c|}
\hline Características & Perspectiva Informacional, de diálogo e de participação \\
\hline $\begin{array}{l}\text { Tipos de } \\
\text { público }\end{array}$ & $\begin{array}{l}\text { População em geral; cidadão comum; produtores rurais, agricultores, } \\
\text { formuladores de políticas públicas; setor empresarial; governo; gestores das } \\
\text { unidades de conservação, comunidades locais e formuladores de políticas } \\
\text { públicas ambientais; populações costeiras; público de ensino formal e não } \\
\text { formal. }\end{array}$ \\
\hline $\begin{array}{l}\text { Arranjos } \\
\text { institucionais }\end{array}$ & $\begin{array}{l}\text { Forte articulação com sistema produtivo, integração da pesquisa ao ensino, } \\
\text { educação básica, pós-graduação; vinculação da pesquisa a programa de educação } \\
\text { em ciências; extensão; sinergia das atividades e interação entre grupos, setor } \\
\text { empresarial e sociedade como critérios de julgamento; plano de divulgação da } \\
\text { ciência como característica obrigatória; estratégia de divulgação científica como } \\
\text { critério de julgamento; resultados da divulgação científica compõem o relatório } \\
\text { final; cofinanciamento com a Capes para formação em nível de pós-graduação. }\end{array}$ \\
\hline $\begin{array}{l}\text { Concepção } \\
\text { de ciência/ } \\
\text { processo de } \\
\text { conhecimento }\end{array}$ & $\begin{array}{l}\text { Redes de pesquisa cooperativas, inter-regionais e interdisciplinares; bem } \\
\text { articuladas com o setor produtivo e com a sociedade; produção conjunta de } \\
\text { material de divulgação científica e de políticas públicas; interdisciplinaridade } \\
\text { ligada à estratégia de divulgação científica; pesquisa deve considerar o } \\
\text { aproveitamento do conhecimento tradicional das populações costeiras e o } \\
\text { desenvolvimento científico, econômico e educacional de populações tradicionais } \\
\text { de áreas costeiras. }\end{array}$ \\
\hline & Editais e Chamadas \\
\hline & Edital nº 15/2008 MCT/ CNPq/FNDCT/CAPES/FAPEMIG/FAPERJ/FAPESP/INCT; \\
\hline \multicolumn{2}{|c|}{ Edital MCT/CNPq nº 023/2009 (Programa Antártico Brasileiro); } \\
\hline \multicolumn{2}{|c|}{ Edital MCT/CNPq/ CT-AGRO nº 24/2009 (Redes de Pesquisa sobre Polinizadores); } \\
\hline \multicolumn{2}{|c|}{ Edital MCT/CNPq/FNDCT/ FAPs/MEC/CAPES/PRO-CENTRO-OESTE nº 031/2010; } \\
\hline \multicolumn{2}{|c|}{$\begin{array}{l}\text { Edital MCT/CNPq/MMA/MEC/CAPES/FNDCT - Ação Transversal/FAPs no 47/2010 (SISBIOTA } \\
\text { BRASIL); }\end{array}$} \\
\hline \multicolumn{2}{|c|}{ Edital MCT/CNPq/FNDCT/ MEC/CAPES/FAPs n 56/2010 (REFLORA); } \\
\hline \multicolumn{2}{|c|}{ Edital MCT/CNPq/FNDCT nº 71/2010 - INCT-Mar; } \\
\hline \multicolumn{2}{|c|}{ Chamada CNPq/ICMBio no 13/2011 (Pesquisa em Unidades de Conservação Federais). } \\
\hline
\end{tabular}

Fonte: Dados da pesquisa dos autores

Em três editais notamos a perspectiva de diálogo articulada com a participação, nos quais destaca-se a articulação com povos indígenas, comunidades tradicionais, agricultores familiares, entre outros. Está presente maior heterogeneidade e precisão na definição dos tipos de público e na forma de articulação para a realização do projeto, por meio de vinculação à extensão rural, evocando perspectivas de diálogo e de construção conjunta. São valorizados a integração dos conhecimentos e o desenvolvimento sustentável das comunidades locais nos objetivos da pesquisa. Incluem documentos com abordagens multidisciplinares, transdisciplinares e interculturais, pressupondo 
interação de conhecimentos, bem como enfoque metodológico participativo, integrando os distintos públicos em todas as etapas da pesquisa - concepção, execução e avaliação dos projetos, que devem ser aprovados pelas legitimidades locais, incentivando o protagonismo e buscando a emancipação social das comunidades e dos povos envolvidos (Quadro 4). Assim, aspectos de participação estão presentes quando as comunidades são envolvidas.

Quadro 4. Características das perspectivas de diálogo e de participação em editais e chamadas sobre Biodiversidade (2005-2012)

\begin{tabular}{|c|c|}
\hline Características & Perspectiva de diálogo e de participação \\
\hline $\begin{array}{l}\text { Formas de } \\
\text { socialização do } \\
\text { conhecimento }\end{array}$ & $\begin{array}{l}\text { Inclusão de projetos de inovação tecnológica para desenvolver ações } \\
\text { de experimentação, validação e disponibilização de tecnologias } \\
\text { apropriadas à agricultura familiar, de modo participativo; } \\
\text { coconstrução. }\end{array}$ \\
\hline Tipos de público & $\begin{array}{l}\text { Comunidades tradicionais; povos indígenas; agricultores familiares de } \\
\text { base ecológica; pescadores familiares; pescadores artesanais; assentados } \\
\text { dos programas de reforma agrária; quilombolas, extrativistas; } \\
\text { aquicultores de base familiar. }\end{array}$ \\
\hline onais & $\begin{array}{l}\text { Extensão e disponibilização de tecnologias sociais e integração } \\
\text { de conhecimento; a construção de parcerias e a implementação } \\
\text { participativa da proposta são critérios de julgamento; integração das } \\
\text { comunidades tradicionais na concepção, execução e avaliação dos } \\
\text { projetos; incentivo ao protagonismo e buscando a emancipação social } \\
\text { das comunidades e dos povos envolvidos. }\end{array}$ \\
\hline $\begin{array}{l}\text { de } \\
\text { esso de } \\
\text { to }\end{array}$ & $\begin{array}{l}\text { Multi, inter e transdisciplinaridade, interculturalidade; metodologias } \\
\text { participativas; interação dialética entre os conhecimentos técnicos, } \\
\text { ecológicos, sociais, econômicos, culturais e políticos; sustentabilidade } \\
\text { das comunidades tradicionais como objetivo da pesquisa; utilização } \\
\text { sustentável dos recursos e repartição dos benefícios da biodiversidade } \\
\text { capazes de viabilizar processos adequados de inovação e difusão } \\
\text { tecnológica em atividades e práticas tradicionais de uso dos recursos } \\
\text { naturais; biodiversidade considerada dentro do contexto cultural, } \\
\text { buscando a construção e a apropriação material e simbólica pelas } \\
\text { comunidades tradicionais e pelos povos indígenas. }\end{array}$ \\
\hline & Editais e Chamadas \\
\hline \multicolumn{2}{|c|}{ Edital MCT/MMA/ SEAP/SEPPIR/CNPq n 26/2005 (Extensão e tecnologias sociais); } \\
\hline \multicolumn{2}{|c|}{$\begin{array}{l}\text { Edital MCT/CNPq/ SEAP-PR/CT-Agronegócio/CT-Verde Amarelo/CT-Saúde/CT-Hidro - nº } \\
\text { 07/2008 (Tecnologias para a agricultura familiar de base ecológica, comunidades tradicionais e } \\
\text { povos indígenas); }\end{array}$} \\
\hline \multicolumn{2}{|c|}{$\begin{array}{l}\text { Edital MCT/CNPq/ MDA/ SAF/ Dater n }{ }^{\circ} 033 / 2009 \text { (Extensão rural no âmbito da agricultura } \\
\text { familiar, comunidades quilombolas, extrativistas, indígenas, pescadores artesanais e aquicultores } \\
\text { de base familiar). }\end{array}$} \\
\hline
\end{tabular}

Fonte: Dados da pesquisa dos autores 


\section{Discussão}

Percebemos no conjunto de editais e chamadas sobre biodiversidade uma predominância do modelo informacional, em que, segundo Navas e Marandino (2009), a necessidade de alcançar um público amplo é o aspecto central que permeia as atividades desenvolvidas na lógica informativa, coincidindo com as estratégias e iniciativas de várias instituições, incluindo as governamentais, que permanecem atribuindo ao cientista (e no caso também aos formuladores de políticas) o papel de direcionar aquilo que o público precisa saber e compreender sobre ciência e tecnologia. Nessa perspectiva, os documentos explicitam a disseminação para os pares, ou, quando preveem a necessidade da divulgação científica, não há referência a tipos de público, restringindo-se à criação de páginas na internet de divulgação do projeto, plataformas de informação, sistemas de informação, base de dados e gerenciamento de repositórios da informação sobre a biodiversidade brasileira, entre outros. Trazem ainda a divulgação científica destinada a um público genérico, à sociedade em geral, ao público beneficiário, podendo ou não apresentar algum arranjo institucional para o alcance dos objetivos.

As críticas ao modelo informacional estão relacionadas à falta de contexto nas questões apresentadas, de relação com o cotidiano e os conhecimentos prévios e outras formas de conhecimento e à apresentação de um conhecimento hierarquizado que privilegia um tipo de ciência sobre um saber popular (Lewenstein \& Brossard, 2006; Lozano-Borda, Pérez-Bustos \& Roatta-Acevedo, 2012). Por outro lado, um aspecto importante a se valorizar nesse modelo estaria relacionado à possibilidade do fornecimento de informação confiável de uma forma acessível, como um pré-requisito fundamental para um diálogo democrático sobre questões de ciência (Dickson, 2005 citado em Massarani, 2012, p.100).

Nos documentos em que são percebidas perspectivas mistas, em que aspectos informacionais estão associados às perspectivas de diálogo e de participação, maior heterogeneidade na consideração dos tipos de público está presente, com arranjos institucionais enriquecidos pela interação com a educação básica e com a pós-graduação, incluindo, em alguns deles, a participação da Capes; interação com a educação ambiental e a extensão. De modo especial, a associação da interdisciplinaridade à estratégia de divulgação científica é requisitada, dando margem à integração de profissionais da educação e comunicação e ainda, em algum grau, inclui aspectos de participação, com a evocação da construção conjunta do conhecimento.

A presença de perspectivas de diálogo e de participação, conjuntamente com perspectivas informacionais, configura uma situação semelhante ao encontrado por Navas (2008), no estudo sobre as ações de popularização da ciência no âmbito do então Ministério da Ciência e Tecnologia - MCT, que revelou a existência de tensões no discurso de popularização da C\&T, permeado tanto por elementos associados ao modelo de déficit, que privilegiam a emissão e a difusão da informação, como por elementos associados ao envolvimento democrático e que buscam uma superação dos modelos tecnocráticos. Constatamos, assim, que atividades de divulgação científica 
podem assumir várias características de dois ou mais modelos (Massarani, 2012) e que os modelos de comunicação não são excludentes, podendo uma mesma iniciativa priorizar conteúdos científicos e o contexto sociocultural desses conhecimentos, da mesma forma que uma mesma atividade pode propor a disseminação de informações em via única e também o diálogo (Navas \& Contier, 2015).

Quanto aos processos de conhecimento, percebemos níveis distintos, multi e interdisciplinares; entretanto parece estar havendo uma tendência ao fomento a redes de pesquisa interdisciplinares, com cooperação entre campos e áreas do conhecimento, incluindo a exigência da inclusão da divulgação científica de modo interdisciplinar e dando margem à interação com profissionais da educação e da comunicação, bem como com a presença de arranjos institucionais vinculados ao sistema de ensino e a programas de pós-graduação, como nos editais e chamadas com apoio da Capes. Tal característica vai ao encontro das perspectivas do Plano Nacional de Pós-Graduação 2011-2020, que possui como um de seus eixos estratégicos a multi e a interdisciplinaridade entre as principais características de pós-graduação e importantes temas da pesquisa, bem como o apoio à educação básica e a outros níveis e modalidades de ensino, especialmente o ensino médio (Philippi Jr, Sobral, Fernandes, \& Sampaio, 2013).

Nos documentos em que a perspectiva de participação esteve presente, constam o incentivo a processos de conhecimento interdisciplinares, transdisciplinares e interculturais e a geração de conhecimento integrado às comunidades locais. Ainda nestes documentos, aparecem os arranjos institucionais destacando a integração da pesquisa e da extensão; a disponibilização de tecnologias sociais com ênfase na integração de conhecimentos, bem como a gestão participativa das unidades de conservação e a solução de conflitos de modo integrado. Conforme Navas e Marandino (2009), fóruns, debates, conferências de consenso, atividades de valorização de saberes locais e tradicionais são alguns exemplos das ações desenvolvidas de acordo com o modelo participativo. Nesse sentido, encontramos sinais da perspectiva Ciência-TecnologiaSociedade, que coloca a extensão, ou seja, o vínculo ciência-sociedade, ou conhecimentosociedade, dentro da esfera da produção de conhecimento, e não fora dela (Davyt \& Lázaro, 2010). Tal aspecto vai ao encontro de uma atualização conceitual da extensão universitária, ao estimular não apenas os aprendizados mútuos, no lugar da tradicional transferência unidirecional de saberes, mas também por integrar a reflexão sobre o contexto social de produção e aplicação dos conhecimentos científico-tecnológicos, para a integração do ensino-pesquisa-extensão (Davyt \& Lázaro, 2010; Freire, 2011; Fórum de Pró-Reitores de Extensão das Instituições de Educação Superior Brasileiras -FORPROEX, 2012; Marandino, 2013). Também permite reconhecer uma perspectiva de participação associada à discussão de problemas, impactos e transformações sociais da C\&T e à identificação de contradições (Strieder \& Kawamura, 2014), sendo que a gestão participativa da unidade de conservação da Chamada 13/2011 evocaria ainda um aspecto da participação associado à participação no âmbito das esferas políticas.

Cumpre ressaltar que encontramos em apenas um edital a integração da 
interculturalidade ao processo de conhecimento, propondo uma abordagem multidisciplinar, transdisciplinar e intercultural, que pressupõe interação dos conhecimentos (Edital MCT/MMA/SEAP/SEPPIR/CNPq n 026/2005). Esse documento inclui o diálogo e a anuência das comunidades e povos indígenas na concepção, execução e avaliação dos projetos, com a valorização do conhecimento tradicional da comunidade e a integração do conhecimento. Tal perspectiva está presente em ações de fomento em que a biodiversidade é evocada em um contexto sociocultural. Esta abordagem não consta de editais e chamadas de programas específicos de biodiversidade, como SISBIOTA, PPBio e Bionorte, contrastando com a extraordinária sociodiversidade brasileira.

Nesta linha, Medeiros e Lima (2014) apontam que vislumbrar uma educação a partir de uma perspectiva intercultural é reconhecer as características diferenciadas dos povos que formam a grande diversidade brasileira, bem como respeitar e entender essa variedade para uma mudança significativa na forma de se pensar o mundo. Também vão ao encontro da reivindicação dos povos indígenas as instituições de ensino superior (IES) brasileiras de promoção dos aspectos interculturais, que ligam as sociedades indígenas às sociedades pertencentes a outras influências culturais, em uma formação que lhes permite integrar conhecimentos e saberes e fortalecer habilidades para se posicionarem à frente da resolução dos problemas, como os relativos à preservação de suas terras, ampliação de direitos, manutenção e difusão de seus próprios saberes. Navas e Marandino (2009) assinalam, na mesma perspectiva, que entre os aspectos-chave que caracterizam atividades dialógicas estão a negociação de conhecimentos sobre diferentes atores sociais e a concepção de ciência contextualizada junto a outras manifestações culturais.

\section{Considerações finais}

A análise dos editais e chamadas relacionados à biodiversidade revela que tem sido incentivada uma prática de comunicação pública da ciência para tornar o tema biodiversidade acessível a outros públicos, que não somente os pares da comunidade científica.

A predominância de perspectivas informacionais, em que são propostas formas de comunicação pública unidirecionais do cientista para o público chama a atenção para a necessidade de se promover a discussão de novas formas de incentivo à relação entre ciência e público no fomento à pesquisa sobre biodiversidade, no sentido de tornar o diálogo com o público mais acessível, em que se faz necessária a escuta pelos cientistas, de modo que as compreensões possam ser desenvolvidas conjuntamente (Trench, 2008), em direção ao novo paradigma da "ciência para o bem da sociedade", em que os conhecimentos locais são incorporados, e o conhecimento se faz de forma predominantemente interdisciplinar e se dá nos locais mais variados, ou seja, é realizado por múltiplos atores (Velho, 2011).

A existência de documentos em que perspectivas de diálogo e de participação 
estão presentes sinaliza avanços em direção à compreensão do papel determinante da sociedade nos rumos da ciência. Aproxima, assim, os referenciais teóricos da área de comunicação pública da ciência com aqueles da educação Ciência-TecnologiaSociedade (Navas et al., 2007; Santos, 2007), permitindo reconhecer o incentivo a alguns níveis distintos de participação, conforme Strieder e Kawamura (2014). O incentivo a formas de comunicação pública que valorizam o diálogo e a participação pública são, portanto, de grande relevância, levando em consideração a diversidade de públicos e a elevada sociodiversidade existente no Brasil, bem como tendo em vista que a conscientização e a participação públicas são essenciais para o alcance das metas globais e nacionais de conservação da biodiversidade, como as Metas de Aichi para 2020. Cumpre ressaltar, nessa direção, que as situações exitosas de conservação e uso sustentável da biodiversidade estão associadas, entre outros aspectos, a quando se dá participação às comunidades indígenas e locais e às partes interessadas (Secretariado da Convenção sobre Diversidade Biológica, 2014), levando-nos a considerar a importância de processos de conhecimento que consideram a interculturalidade.

A existência de vários editais e chamadas integrados em redes de conhecimento interdisciplinares dá margem a avaliar que esteja sendo estruturada uma capacidade de pesquisa essencial diante da complexidade da temática ambiental em que a biodiversidade está imersa e que requer o incentivo e a valorização do diálogo, com a integração dos conhecimentos de disciplinas diferentes e associados à expertise do conhecimento local. Essa estrutura de pesquisa se beneficiaria de arranjos em forma de redes de conhecimento não hierárquicas, que facilitariam o processo de conhecimento interdisciplinar e o exercício de desenvolvimento de linguagens para uma boa comunicação entre as áreas (Brown, Deletic \& Wong, 2015).

A metodologia da Análise Textual Discursiva (Moraes \& Galiazzi, 2007) possibilitou estabelecer as categorias referentes à concepção de ciência, arranjos institucionais, formas de socialização do conhecimento e tipos de público, que relacionamos aos modelos de comunicação pública da ciência, permitindo uma nova compreensão sobre os documentos analisados. Consideramos que análise dos editais e chamadas sobre biodiversidade, ao revelar aspectos que distinguem perspectivas de relações entre ciência e público, pode permitir aos pesquisadores considerar a inserção de ações de educação e divulgação científica, ao proporem um projeto de pesquisa. Além disso, a análise a partir das categorias propostas possibilita que tais ações privilegiem aspectos que favoreçam novos modos de relações entre os pesquisadores e as próprias pesquisas e os distintos públicos, no sentido de que tais relações sejam mais dialógicas e participativas. De modo especial, consideramos que este estudo poderá contribuir para os formuladores dos editais e chamadas, nas agências de fomento à pesquisa, no sentido de que possam buscar uma coerência entre a concepção de ciência expressa na ação de fomento, os arranjos institucionais recomendados, os tipos de público para os quais as ações e materiais de divulgação são propostos e as formas de socialização do conhecimento que são indicadas, de modo que possam avançar na democratização do 
conhecimento e no incentivo a modos de relações entre ciência e públicos que fortaleçam a participação da sociedade.

A questão da linguagem, ao se pensar na estreita relação entre a ciência da biodiversidade e a da sustentabilidade, requer que se restabeleçam conexões entre linguagem e cultura, promovendo o alcance de uma visão embasada no pluralismo e no diálogo (Colucci-Gray et al., 2013). Conforme a quarta edição da Perspectiva Mundial sobre a Diversidade Biológica, os esforços podem e devem fortalecer-se mediante a compreensão dos vínculos críticos que existem entre a diversidade biológica e o desenvolvimento sustentável, incluindo a redução da pobreza com a conservação da natureza (Scarano, 2014; Secretariado da Convenção sobre Diversidade Biológica, 2014). Nesse contexto, as pesquisas em biodiversidade, nos diferentes programas de pesquisa, podem subsidiar a ciência da sustentabilidade, que defende a colaboração interdisciplinar e interparadigmática, inclui os requerimentos da ciência pós-normal e propõe um diálogo respeitoso entre especialistas e não especialistas na construção de um novo conhecimento científico (Colucci-Gray et al., 2013). Como parte dessa tendência está a integração entre ciências sociais e ciências naturais e uma política científica mais integrada com outros atores, de forma a estabelecer um novo contrato entre ciência e sociedade, conforme enfatizado no penúltimo fórum mundial da ciência, ocorrido no Brasil, em 2013, como parte das recomendações para a agenda pela sustentabilidade global, presentes no documento "Futuro da Terra", que se alinha ao modelo conceitual da Plataforma Intergovernamental de Biodiversidade e Serviços Ecossistêmicos (IPBES) (Díaz et al., 2015; Joly, 2013). Tal integração das ciências sociais às redes de pesquisa e plataformas de conhecimento facilitaria ainda a explicitação de controvérsias (Viseu, 2015) e iria ao encontro das plataformas do conhecimento (Victor, 2015), bem como de um grau de participação no âmbito educacional associado à discussão das limitações do conhecimento científico, à abordagem de temas controversos e/ou ainda não estabelecidos, associados a uma perspectiva de participação no nível de compreensão de políticas públicas (Strieder \& Kawamura, 2014).

Assim, acreditamos que o debate sobre a importância da ciência e tecnologia nas sociedades da informação e do conhecimento requer que sejam orientados os processos, definidas as prioridades e, para ser válido, incluído o reconhecimento da importância dos saberes tradicionais, com base nos quais boa parte da sociedade sobrevive social e culturamente (Martín-Barbero, 2004). Requer reconhecer o direito à participação do e no conhecimento; o direito aos cidadãos e grupos sociais ao acesso à informação não apenas como receptores, mas também como produtores. Desse modo, o direito à informação relaciona-se ao direito à comunicação em sua mais alta complexidade, ao direito à comunicação pública do conhecimento:

[...] o que se busca salvaguardar é, ao mesmo tempo, o direito para que a sociedade possa seguir contando com esse outro conhecimento que provem dos saberes de experiência social, e o direito a que tudo o que se refere às opções e decisões sobre desenvolvimento e investimento em pesquisa científica e tecnológica possa ser objeto de informação e 
debate públicos. (Martín-Barbero, 2004, p. 43)

Diante desse panorama, acreditamos que os editais e chamadas públicas constituem um instrumento valioso a ser aprimorado por meio de amplo debate, em que se destaca a relevância das discussões em torno da abordagem Ciência-Tecnologia-Sociedade, para que se possam alcançar novas relações entre ciência e público, que estimulem a troca de saberes, a discussão de temas controversos e fortaleçam o protagonismo da sociedade nos rumos da ciência e na conservação da biodiversidade.

\section{Agradecimentos}

Agradecemos pelo apoio ao $\mathrm{CNPq}$, aos docentes e discentes do Programa de PósGraduação em Educação em Ciências da Universidade Federal do Rio Grande - FURG e aos integrantes do Grupo de Estudo e Pesquisa em Educação Não Formal e Divulgação em Ciências da Faculdade de Educação - GEENF/USP. Agradecemos de modo especial aos Professores Maria do Carmo Galiazzi (FURG), Douglas Falcão (MCTI/MAST) e Wildson Luiz Pereira dos Santos (UnB-in memorian), bem como aos revisores anônimos deste trabalho, pelos enriquecedores comentários e sugestões.

\section{Referências}

Alves-Mazzotti, A. J., \& Gewandsznajder, F. (2004). O método nas ciências naturais e sociais. São Paulo, SP: Pioneira Thomson Learning.

Auler, D. (2002). Interações entre ciência-tecnologia-sociedade no contexto da formação de professores de ciências. (Tese de Doutorado, Programa de Pós-Graduação em Educação da Universidade Federal de Santa Catarina, Florianópolis).

Brown, R. R., Deletic, A., \& Wong, T. H. F. (2015). Interdisciplinarity: how to catalyse collaboration. Nature, 525(317), 315-317. doi: 10.1038/525315a

Bucchi, M. (2008). Of deficits, deviations and dialogues: theories of public communication of science. In M. Bucchi, \& B. Trench (Eds.). Handbook of public communication of science and technology (pp.57-76). New York, NY: Routledge.

Bucchi, M., \& Trench, B. (2016). Science communication and Science in Society: A conceptual Review in ten keywords. Tecnoscienza - Italian Journal of Science \& Technology Studies, 7(2), 151-168.

Cheng, D. H., Claeseens, M., Gascoigne, T., Metcalfe, J., Schiele, B., \& Shi, S. (2008). Introduction: Science Communication - A Multidisciplinary and Social Science. In D. H. Cheng, M. Claeseens, T. Gascoigne, J. Metcalfe, B. Schiele, \& S. Shi, (Eds.). Communicating science in social contexts: new models, new practices (pp. 1-3). New York, NY: Springer.

Colucci-Gray, P., Dodman, A. M., \& Camino, E. (2013). Science education for sustainability, epistemological reflections and educational practices: From natural sciences to trans-disciplinarity. Cultural Studies of Science Education, 8(1), 127-183. doi: 10.1007/s11422-012-9405-3 
Comissão Nacional da Biodiversidade. Conabio. (2013). Resolução Conabio no 6, de 3 de setembro de 2013. Dispõe sobre as metas nacionais de biodiversidade para 2020. Disponível em http://portaldabiodiversidade.sp.gov.br/files/2014/06/Metas-NacionaisCONABIO.pdf

Contier, D., Navas, A. M., \& Marandino, M. (2007). Qual a participação? Um enfoque CTS sobre os modelos de comunicação pública da ciência nos museus de ciência e tecnologia. Memoria da X Reunion de la Red de Popularización de la Ciencia y la Tecnología en América Latina y el Caribe. San José, Costa Rica.

Davyt, A., \& Lazaro, M. (2010). El campo CTS y el enfoque extensionista de la Universidad Latinoamericana: diálogos y convergencias. Actas de la VIII Jornadas Latinoamericanas de Estudios Sociales de la Ciencia y la Tecnología. Buenos Aires, Argentina.

Declaração do Estado do Planeta. (2012). Planet under pressure: new knowledge towards solutions. Londres, Inglaterra. Disponível em http://www.gci.org.uk/Documents/PuP Declaration_2012-03-29_FINAL_29Mar_0851_.pdf

Díaz, S., Ash, N., Demissew, S., Carabias, J., Joly, C., Lonsdale, W...\&\& Zlatanova, D. (2015). The IPBES Conceptual Framework (connecting nature and people). Current Opinion in Environmental Sustainability, 14, 1-16. doi: 10.1016/j.cosust.2014.11.002

Dickson, D. (2005). The case for a "deficit model" of science communication. Recuperado de http://www.scidev.net/en/editorials/the-case-for-a-deficit-model-of-science-communic.html Freire, P. (2011). Extensão ou comunicação? (15a ed.). São Paulo: Paz e Terra.

Fórum de Pró-Reitores de Extensão das Instituições de Educação Superior Brasileiras. Forproex. (2012). Plano Nacional de Extensão Universitária. Disponível em https://www. ufmg.br/proex/renex/images/documentos/2012-07-13-Politica-Nacional-de-Extensao. pdf

Instituto Brasileiro de Geografia e Estatística. IBGE. (2011). Censo Demográfico 2010. Rio de Janeiro, RJ: IBGE.

Instituto Socioambiental. ISA. (2015). Quadro geral dos povos. Disponível em http:// www. pib.socioambiental.org/pt/c/quadro-geral

Joly, C. A. (2013). The expected role of IPBES. [Editorial]. Biota Neotropica, 13(1).

Joly, C. A., Bolzani, V. S., Haddad, C. F. B., Metzger, J. P., Oliveira, M. C., Rodrigues, R. R., \& Verdade, L. M. (2010). Biodiversity Conservation Research, Training, and Policy in São Paulo. Science, 328, 1358-1359. doi: 10.1126/science.1188639

Lewenstein, B. V. (2003). Models of Public Communication of Science \& Technology. Disponível em http://communityrisks.cornell.edu/BackgroundMaterials/Lewenstein2003. pdf 
Lewenstein, B. V., \& Brossard, D. (2006). Assessing models of public understanding in ELSI outreach materials. Recuperado de https://ecommons.cornell.edu/bitstream/ handle/1813/5242/Lewenstein\%20and\%20Brossard.2006.DOE\%20final\%20report. pdf? sequence $=1$

Lewinsohn, T. M. (2010). The ABECO and the Brazilian Forest Code. Natureza \& Conservação, 8, 100-101.

Lozano-Borda, M., Pérez-Bustos, T., \& Roatta-Acevedo, C. (2012). Deconstruyendo el modelo deficitario de la apropiación social de la ciencia y la tecnología en Colombia: el caso de la cartilla "Las Maticas de mi Huerta". Educar em Revista, (44), 93-109. doi: 10.1590/S0104-40602012000200007

Marandino, M. (2009). Museus de ciências, coleções e educação: relações necessárias. Museologia e Patrimônio, 2 (2), 1-12.

Marandino, M. (2011). Por uma didática museal. (Tese de Livre Docência, Faculdade de Educação da Universidade de São Paulo, São Paulo).

Marandino, M. (2013). Educação, ciência e extensão: a necessária promoção. Revista de Cultura e Extensão, 9, 89-102. doi: 10.11606/issn.2316-9060.v9i0p89-100

Marandino, M. (2015). Sobre a pesquisa e a prática em educação e comunicação da ciência: reflexões e desafios. Pensar a Educação em Pauta. Disponível em http://www. pensaraeducacaoempauta.com/?fb_comment_id=949431841763823_95009403169760 4\#!martha-marandino-03jun/c1ewv

Marandino, M., Bizerra, A., Daré, M. P., Garcia, V. A. R., Monaco, L., Martins, L., ... Standerski, L. (2008). Educação em museus: a mediação em foco (1a ed.). São Paulo: FEUSP.

Martín-Barbero, J. (2004). Lectura de la encuesta: la percepción que tienen los colombianos sobre la ciencia y la tecnología. In Departamento Administrativo de Ciencia, Tecnología e Innovación Colciencias (pp. 41-47). Bogotá, Colômbia: Colciencias.

Massarani, L. (2012). Comunicação da ciência e apropriação social da ciência: algumas reflexões sobre o caso do Brasil. Uni-pluri, 12, 92-100.

Massarani, L., \& Moreira, I. (2009). Ciência e público: Reflexões sobre o Brasil. Redes, 15(30), 105-124.

Medeiros, I. A., \& Lima, J.H. S. (2014). Diálogo de saberes no Instituto dos Conhecimentos Indígenas e Pesquisa do Rio Negro (AM). Parcerias Estratégicas, 19(39), 35-48.

Metzger, J. P., Joly, C. A., Lewinsohn, T., Rodrigues, R. R., \& Verdade, L. M. (2010). Brazilian law: full speed in reverse. Science, 329(5989), 276-277. doi: 10.1126/ science.329.5989.276-b 
Ministério da Ciência e Tecnologia. MCT. (2010). Livro Azul da $4{ }^{a}$ Conferência Nacional de Ciência e Tecnologia e Inovação para o Desenvolvimento Sustentável. Brasília, DF: Ministério da Ciência e Tecnologia/ Centro de Gestão e Estudos Estratégicos.

Mittermeier, R. A., Brooks, T., Fonseca, G. A. B., Gil, R. P., Hoffman, M., Lamoreux, J., ... Pilgrim, J. (2005). Hotspots revisited: earth's biologically richest and most endangered terrestrial ecoregions (2a ed.). Boston, MA: University of Chicago Press.

Moraes, R., \& Galiazzi, M. C. (2007). Análise textual discursiva. Ijuí, RS: Unijuí.

Moreira, I. C. (2006). A popularização da ciência e tecnologia como um elemento de inclusão social. Inclusão Social, 1(2), 11-16.

Moreira, I. C., \& Massarani, L. (2002). Aspectos históricos da divulgação científica no Brasil. In M. F. Brito, L. Massarani, \& I. C. Moreira (Orgs.). Ciência e público: caminhos da divulgação científica no Brasil (pp. 43-64). Rio de Janeiro, RJ: Casa da Ciência.

Navas, A. M. (2008). Concepçães de popularização da ciência e da tecnologia no discurso político: impactos nos museus de ciências. (Dissertação de Mestrado em Educação). Universidade de São Paulo, São Paulo.

Navas, A. M., \& Contier, D. (2015). Projetos de divulgação científica: um olhar crítico. In D. Contier, \& M. Marandino (Orgs.). Educação Não Formal e Divulgação em Ciência: da produção do conhecimento a ações de formação (pp. 78-84). São Paulo, SP: Faculdade de Educação da USP.

Navas, A. N., Contier, D., \& Marandino, M. (2007). Controvérsia científica, comunicação pública da ciência e museus no bojo do movimento CTS. Ciência \& Ensino, 1, 1-12.

Navas, A. N., \& Marandino, M. (2009). Dimensión política de la popularización de la ciencia y la tecnología en América Latina. El caso de Brasil. Ciencias, 96, 48-56.

Philippi Jr., A., Sobral, M. C., Fernandes, V., \& Sampaio, C. A. C. (2013). Desenvolvimento sustentável, interdisciplinaridade e ciências ambientais. Revista Brasileira de PósGraduação, 10, 509-533. doi: 10.21713/2358-2332.2013.v10.423

Santos, W. L. P. (2007). Educação científica na perspectiva de letramento como prática social: funções, princípios e desafios. Revista Brasileira de Educação, 12(36), 474-492. doi: 10.1590/S1413-24782007000300007

Santos, W. L. P. (2008). Educação científica humanística em uma perspectiva freireana: resgatando a função do ensino de CTS. Alexandria Revista de Educação em Ciência e Tecnologia, 1(1), 109-131.

Santos, W. L. P., \& Auler, D. (Orgs.) (2011). CTS e educação científica: desafios, tendências e resultados de pesquisa. Brasília, DF: Editora Universidade de Brasília.

Santos, W. L. P., \& Mortimer, E. F. (2001). Tomada de decisão para ação social responsável no ensino de ciências. Ciência \& Educação(Bauru), 7(1), 95-111. doi: 10.1590/S151673132001000100007 
Scarano, F. R. (2007). Perspectives on biodiversity science in Brazil. Scientia Agricola, 64 (4), 439-447. doi: 10.1590/S0103-90162007000400016

Scarano, F. R. (2014). Ecossistemas como base para adaptação: um papel para a América Latina no novo acordo global. Pontes, 10(9), 6-7.

Scarano, F. R., Guimarães, A., \& Silva, J. M. (2012). Rio+20: Lead by example. Nature, 486, 25-26. doi: 10.1038/486025a

Scarano, F. R., \& Martinelli, G. (2010). Brazilian List of Threatened Plant Species: Reconciling Scientific Uncertainty and Political Decision-Making. Natureza \& Conservação, 8(1), 13-18. doi: 10.4322/natcon.00801002

Secretariado da Convenção sobre Diversidade Biológica. (2014). Panorama da Biodiversidade Global 4. [Versão Digital]. Disponível em https://nacoesunidas.org/wpcontent/uploads/2015/04/PNUMA_Panorama-Biodiversidade-Global-4.pdf

Secretariat of the Convention on Biological Diversity. (2010). Aichi Biodiversity Targets. Recuperado de https://www.cbd.int/doc/strategic-plan/2011-2020/Aichi-Targets-EN. pdf

Seki, L. (1999). A linguística indígena no Brasil. DELTA: Documentação de Estudos em Linguística Teórica e Aplicada, 15(spe), 257-290. doi: 10.1590/S0102-44501999000300011

Souza, M. P. C. (2009). O papel educativo dos jardins botânicos: análise das ações educativas do Jardim Botânico do Rio de Janeiro. (Dissertação de Mestrado, Faculdade de Educação da Universidade de São Paulo).

Strieder, R. B. (2012). Abordagens CTS na educação científica no Brasil: sentidos e perspectivas. (Tese de Doutorado, Programa Interunidades em Ensino de Ciências da Universidade de São Paulo, São Paulo).

Strieder, R. B., \& Kawamura, M. R. D. (2014). Perspectivas de participação social no âmbito da educação CTS. Uni-pluri, 14(2), 101-110.

Trajano, E. (2010). Políticas de conservação e critérios ambientais: princípios, conceitos e protocolos. Estudos Avançados, 24(68), 135-146. doi: 10.1590/S010340142010000100012

Trajano, E., \& Varjabedian, R. (2009, 03 de julho). O conhecimento biológico e sua aplicação no universo da gestão ambiental: aspectos conceituais e metodológicos. JC E-mail. Disponível em http://www.jornaldaciencia.org.br/edicoes/?url=http://jcnoticias. jornaldaciencia.org.br/14-o-conhecimento-biologico-e-sua-aplicacao-no-universo-dagestao-ambiental-aspectos-conceituais-e-metodologicos-texto-de-eleonora-trajanoe-roberto-varjabedian/ 
Trench, B. (2008). Towards an analytical framework of science communication models. In D. H. Cheng, M. Claeseens, T. Gascoigne, J. Metcalfe, B. Schiele, \& S. SHI (Eds.). Communicating Science in Social Contexts: new models, new practices (pp. 119-135). Dordrecht, Netherlands: Springer Science \& Business Media.

Trench, B., \& Bucchi, M. (2010). Science communication, an emerging discipline. Journal of Science Communication, 9(2), 1-5.

Velho, L. (2011). Conceitos de ciência e a Política Científica, Tecnológica e de Inovação. Sociologias, 13(26), 128-153. doi: 10.1590/S1517-45222011000100006

Victor, D. (2015). Climate change: embed the social sciences in climate policy. Nature, 520, 27-29. doi:10.1038/520027a

Viseu, A. (2015). Integration of social science into research is crucial. Nature, 525, 291. doi:10.1038/525291a

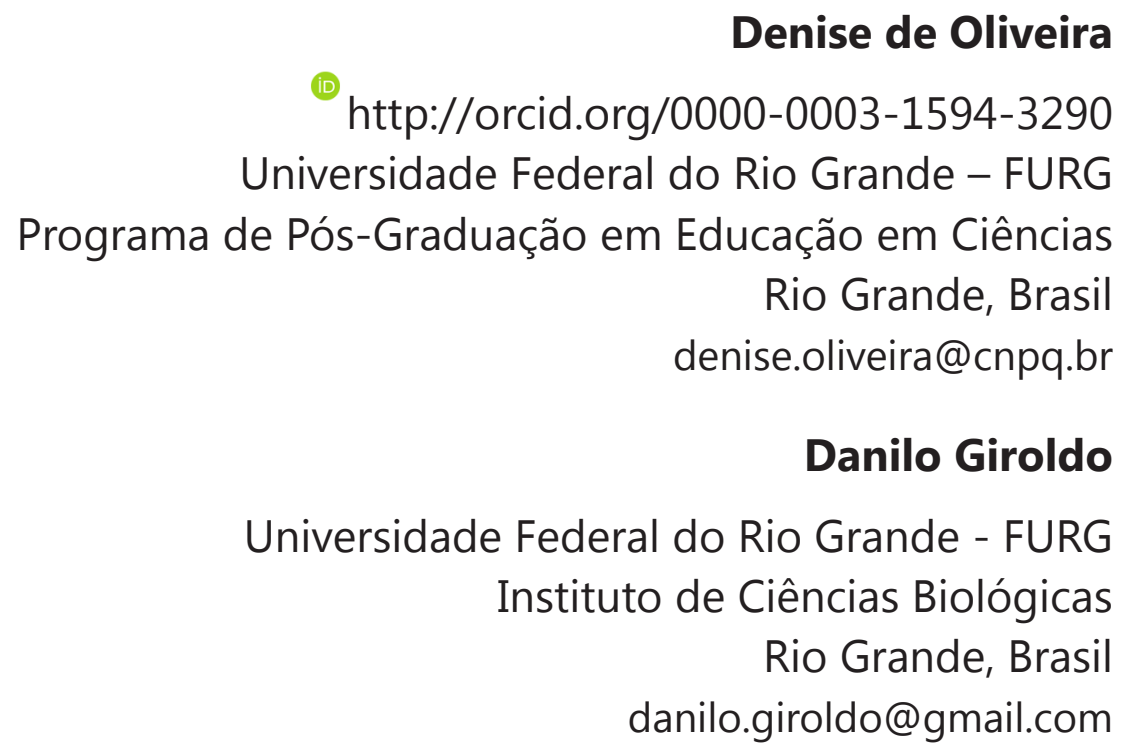

Martha Marandino

๑ http://orcid.org/0000-0001-9175-012X Universidade de São Paulo - USP

Faculdade de Educação São Paulo, Brasil marmaran@usp.br

Submetido em 03 de Maio 2016

Aceito em 21 de Fevereiro 2017

Publicado em 30 de Abril de 2017 